\title{
Review
}

\section{Androgens and male aging: current evidence of safety and efficacy}

\author{
Louis J. Gooren
}

Department of Endocrinology, VU University Medical Center, Amsterdam 1007 MB, the Netherlands

\begin{abstract}
Many signs of aging, such as sexual dysfunction, visceral obesity, impaired bone and muscle strength, bear a close resemblance to features of hypogonadism in younger men. The statistical decline of serum testosterone in aging men is solidly documented. It has been presumed that the above features of aging are related to the concurrent decline of androgens, and that correction of the lower-than-normal circulating levels of testosterone will lead to improvement of symptoms of aging. But in essence, the pivotal question whether the age-related decline of testosterone must be viewed as hypogonadism, in the best case reversed by testosterone treatment, has not been definitively resolved. Studies in elderly men with lower-than-normal testosterone report improvement of features of the metabolic syndrome, bone mineral density, of mood and of sexual functioning. But as yet there is no definitive proof of the beneficial effects of restoring testosterone levels to normal in elderly men on clinical parameters. Few of these studies meet as yet rigorous standards of scientific enquiry: double-blind, placebo-controlled design of the study. The above applies also to the assessment of safety of testosterone administration to elderly men. There is so far no convincing evidence that testosterone is a main factor in the development of prostate cancer in elderly men and guidelines for monitoring the development of prostate disease have been developed. It is of note that there are presently no long-term safety data with regard to the prostate. Polycythemia is another potential complication of testosterone treatment. It is dose dependent and can be managed with dose adjustment.
\end{abstract}

Asian Journal of Andrology (2010) 12: 136-151. doi: 10.1038/aja.2010.4; published online 15 February 2010.

Keywords: aging, bone mineral density, metabolic syndrome, polycythemia, prostate disease, sexual dysfunction, sleep apnea, testosterone

\section{Introduction}

When Prof. Alex Vermeulen from Gent/Belgium in the 1970s started his pioneering work on the decline of testosterone levels in aging men, his work seemed to most professionals only of theoretical interest (for

Correspondence to: Prof. Louis J. Gooren, Department of Endocrinology, VU University Medical Center, P.O. Box 7057, Amsterdam $1007 \mathrm{MB}$, the Netherlands.

Present address: 72/1 moo1, T.Palan, A.Doisaket, Chiang Mai 50220, Thailand.

Fax: +66-5334-7742

Received: 13 January 2010

Accepted: 27 January 2010
E-mail: louisjgooren@gmail.com

Revised: 24 January 2010

Published online: 15 February 2010 review:[1]). But further studies have substantiated that, with age, a significant percentage of men over the age of 60 years have serum testosterone levels below the lower limits of normal for young adult men (aged 20-30 years) [2, 3]. Now, 30-40 years later, the pathophysiological implications of this decline, sometimes amounting to outright testosterone deficiency, have become clearer.

Until a decade ago the ailments of elderly men, such as atherosclerosis, hypertension, diabetes mellitus, lower urinary tract symptoms and erectile dysfunction (ED), were regarded as distinct diagnostic/therapeutic entities but there is a growing evidence that these entities are not disparate and, to improve the health of the aging male, require an integral approach. There is 
an interdependence between the metabolic syndrome, ED and patterns of testosterone in aging men $[4,5]$. The main features of the metabolic syndrome are abdominal obesity, insulin resistance, hypertension and dyslipidemia, significant factors in the etiology of erectile functions. The metabolic syndrome is associated with lower-than-normal testosterone levels [6, 7]. Testosterone is a determinant of glucose homeostasis and lipid metabolism [8] and plays also a significant role in the development and maintenance of bone and muscle mass. Testosterone is not only a factor in libido but exerts also essential effects on the anatomical and physiological substrate of penile erection [9]. The effects of phosphodiesterase type 5 (PDE5)-inhibitors are suboptimal in the presence of hypogonadal values of circulating testosterone [9]. A relationship between lower urinary tact symptoms (LUTS) and circulating levels of testosterone has been difficult to prove but the association of LUTS with the metabolic syndrome and with ED is well established in the literature [10]. Testosterone treatment of hypogonadal not only improves features of the metabolic syndrome but also improves LUTS [11]. With these recent insights, the health problems of elderly men must be placed in a context that allows an integral approach. On the basis of recent insights, diagnosis of testosterone deficiency should be part of the diagnostic work-up of the above conditions.

\section{Late onset hypogonadism (LOH) vs. classical hypogonadism}

Many signs and symptoms of aging, such as sexual dysfunction, visceral obesity, impaired bone and muscle strength, mood disturbances bear a close resemblance to features of hypogonadism in younger men. In younger men improvement of the symptoms of hypogonadism upon testosterone replacement has been convincingly proven. Presently, the statistical decline of serum testosterone in aging men is solidly documented $[1,3]$. So, it is tempting to associate the above described features of aging to the concurrent decline of androgen action in the elderly, and to assume that correction of the lower-than-normal circulating levels of testosterone will lead to improvement of signs and symptoms of aging. But in essence, the pivotal question whether the age-related decline of testosterone must be viewed as hypogonadism, i.e. a deficiency of testosterone manifesting itself with clinical signs and symptoms of insufficient androgen action, and in the best case reversed by testosterone treatment, has not been definitively resolved. This point has been eloquently made in a paper by Handelsman and Liu [12], cautioning against a too facile prescription of testosterone to aging men in the hope to improve, or even reverse, signs and symptoms of aging. The authors argue for well-designed, placebo-controlled double-blind studies documenting unequivocally the benefits of restoring testosterone levels in elderly men to the normal range while also closely monitoring the risks of testosterone administration to aging men. The present studies trying to prove the point have a less-than-optimal design (not blinded, not placebocontrolled) and understandably, in the time frame of the study, usually document surrogate markers of a disease and not clinical endpoints. For instance, do men whose features of the metabolic syndrome improve upon testosterone treatment, have a lower risk of type 2 diabetes mellitus and cardiovascular disease? Even more difficult to prove over a relatively short period of a clinical study: do men whose bone mineral density (BMD) improves upon testosterone treatment have a reduction in fracture rate? To document such an effect, long-term studies are needed.

\section{Who is truly testosterone-deficient in old age?}

As indicated above, circulating levels of testosterone decline with aging. The vast majority of men will have circulating testosterone values which are $5 \%$ $20 \%$ below reference values for men. And it has been difficult to draw a clear dividing line between blood levels of testosterone which represent a hypogonadal and a eugonadal state. In addition, blood testosterone thresholds for androgen deficiency symptoms are highly consistent within a person but differ between people [13]. Hypogonadal men who receive androgen treatment perceive the threshold for androgen deficiency symptoms at highly reproducible blood testosterone levels. This distinctively individual trigger level for androgen deficiency symptoms differs, however, widely between men. The threshold varies from very low to values above the lower limit of the eugonadal reference range. On average it approximates the lower limit of the eugonadal reference range for young men [13]. The factors which define this symptomatic threshold are as yet unknown but it is reasonable to assume that genetic polymorphisms of the androgen receptor 
influencing androgen sensitivity play a significant role $[14,15]$. The impact of the aging process and acquired chronic disease with aging on the threshold for androgen deficiency symptoms are presently uncharted territory [13]. Another issue is whether an age-specific reference range of testosterone values is appropriate for diagnosing testosterone deficiency in old age. Most population studies show that obesity and/or disease and lifestyle has a profound impact on values of testosterone $[16,17]$. There is as present no published evidence that use of age-appropriate reference values offers advantages over use of reference values of the general population but it is an important point in the conceptualization of the desirability of testosterone treatment of elderly men.

\section{Thresholds and dose-response relationships of androgen effects}

The concept of threshold values of circulating testosterone for manifestation of androgen deficiency symptoms, is only beginning to be supported by empirical evidence. A couple of studies have suggested a threshold for androgen effects on male sexual function, primarily libido, becoming evident at the lower range of reference values of blood testosterone concentrations $[18,19]$. These studies were, however, not able to define explicitly such a threshold. Conversely, muscle appears to exhibit linear dose-response relationship to testosterone from below to above the eugonadal reference range for blood testosterone concentrations [20]. One study has suggested a dose-response relationship for effects of normalization of circulating testosterone on features of the metabolic syndrome [21], but an optimal range for those beneficial effects was not established in this study. Whether linear dose-response or threshold models apply to other androgen-sensitive tissues, such as bone and prostate, psychosexual and cardiovascular effects remains to be determined. So, from recent studies of elderly men it has become apparent that spectrum of complaints of testosterone deficiency cannot be related to a specific threshold of testosterone concentrations, but that thresholds vary with the various symptoms of testosterone deficiency [22]. In a cohort of men androgen-related loss of libido or vigor became more prevalent when testosterone concentrations fell below [15] nmol per liter, while depression and diabetes mellitus type 2 (also in nonobese men) were significantly more present in men with testosterone concentrations below $10 \mathrm{nmol} \mathrm{L}^{-1}$. Symptoms related to androgen deficiency in this study could be subdivided in three independent groups: psychosomatic complaints, metabolic disorders, and sexual health problems. Patients suffering from one of these three groups exhibit distinct features in terms of androgen levels, age, and body mass index. So, complaints are not only linked to androgen levels but age and body mass index carried weight as well in the manifestation of signs and symptoms of androgen deficiency [22]. To further complicate the matter of the relationship between testosterone levels on the one hand and symptoms of testosterone deficiency on the other, the authors have drawn attention to the multifactorial impact on certain androgen-related functions [22]. ED may serve as an example of a composite dysfunctionality in which, apart from testosterone concentrations, arterial endothelial function, neuronal integrity and psychological factors play pivotal roles $[23,24]$, almost precluding the establishment of a straightforward relationship between testosterone levels and erectile dysfunction. In the study of Zitzmann et al. [22] ED was identified as a composite pathology of metabolic risk factors, smoking, and depression, and only testosterone concentrations below $8 \mathrm{nmol} \mathrm{L}^{-1}$ contributed to that symptom. So, the various symptoms of $\mathrm{LOH}$ might start at various circulating concentrations of androgens. With a given plasma testosterone level, some complaints might be present and others not. This has also been confirmed in other studies establishing symptom-specific thresholds of androgen levels [1, 2, 25-27]. It, therefore, comes as no surprise that there is a significant variation among clinics and European countries in their application of threshold values of testosterone signifying hypogonadism which range from 7.5 to $12.0 \mathrm{nmol} \mathrm{L}^{-1}$ [28]. Almost certainly a factor in this observation is that physicians in different countries will have different concepts of what constitute the core symptoms of hypogonadism. On the basis of the above observations it is clear that the symptoms of testosterone deficiency are not uniformly and predictably related to values of blood testosterone, which may lead to different diagnostic criteria for testosterone deficiency. So, the conclusion seems inevitable that the clinical manifestations of hypogonadism are multifactorially determined and that the diagnosis should not only depend on the measurement of testosterone but proper assessment should comprise somatic and psychological 
aspects in addition to measurement of testosterone [29].

\section{Diagnosis of LOH}

The diagnosis of $\mathrm{LOH}$ and, certainly, the decision to provide androgen treatment must be made with caution, taking the specific increment of symptom prevalence in relation to testosterone levels into account. The above being the case, it is virtually impossible to take a blood testosterone value as a sole indication for testosterone treatment. The presenting symptom of hypogonadism in a man may or may not be related to that testosterone value, though the lower the value of blood testosterone, the greater the likelihood. A decision to provide androgen treatment must not only be guided by the levels of blood testosterone but, based on clinical judgment, more the likelihood that symptoms are related to that particular testosterone level. The decision to treat will have an element of arbitrariness unless testosterone is truly low $(<6 \mathrm{nmol}$ $\left.\mathrm{L}^{-1}\right)$ or truly in the normal range $\left(>15 \mathrm{nmol} \mathrm{L}^{-1}\right)$. A case can be made for a therapeutic trial of testosterone if the interpretation of clinical and laboratory data provide an ambiguous outcome [30, 31]. In case of sexual dysfunction this approach was helpful in treating the disorder [32].

In summary, physicians have to be aware that testosterone plays a significant but not all-decisive role in older male patients and that replacement options should be based on symptoms and on hormone concentrations, which should be evaluated on a symptom-specific basis. Physicians treating elderly men should have expertise in the signs and symptoms of testosterone deficiency which have a broad spectrum of psychological, metabolic and sexual symptoms. Naturally, testosterone is not a panacea of the all the mental and somatic problems men encounter in the process of aging, and indiscriminate use in men who present with vague symptoms will have many failures.

In patients at risk or suspected of hypogonadism, a thorough physical and biochemical work-up is necessary. Transient decreases of serum testosterone levels such as those due to acute illnesses should be excluded by careful clinical evaluations and repeated hormone measurement. Hypogonadism (primary or secondary) can occur at all ages including elderly men. Risk factors for hypogonadism in older men may include chronic illnesses (including diabetes mellitus, chronic obstructive lung disease, inflammatory arthritic disease, renal disease, and HIV-related disease), obesity, metabolic syndrome, and hemochromatosis. A serum sample for total testosterone determination should be obtained between 07:00 and 11:00 hours. The most widely accepted parameters to establish the presence of hypogonadism is the measurement of serum total testosterone. There are no generally accepted lower limits of normal. There is, however, general agreement that the total testosterone level above $12 \mathrm{nmol} \mathrm{L}^{-1}\left(350 \mathrm{ng} \mathrm{dL}^{-1}\right)$ does not require substitution. Similarly, based on the data of younger men, there is consensus that patients with serum total testosterone levels below $8 \mathrm{nmol} \mathrm{L}^{-1}\left(230 \mathrm{ng} \mathrm{dL}^{-1}\right)$ will usually benefit from testosterone treatment. If the serum total testosterone level is between 8 and $12 \mathrm{nmol} \mathrm{L}^{-1}$, repeating the measurement of total testosterone with sex hormone-binding globulin (SHBG) to calculate free testosterone or free testosterone by equilibrium dialysis may be helpful. Measurements of serum luteinizing hormone will assist in differentiating between primary and secondary hypogonadism and serum prolactin is indicated when the serum testosterone is lower than $5.2 \mathrm{nmol} \mathrm{L}^{-1}\left(150 \mathrm{ng} \mathrm{dL}^{-1}\right)$ or when secondary hypogonadism is suspected. Since there are known variations between assay methods, it is imperative that the practitioners utilize reliable laboratories and are acquainted with the reference ranges for testosterone from their local laboratory [31]. Current immunometric methods for the measurement of testosterone can distinguish between hypogonadism and normal adult men. However, the methods based on mass spectrometry are more accurate and precise [31], and are increasingly recognized as the method of choice for serum testosterone measurement. The measurement of free or bioavailable testosterone should be considered when the serum total testosterone concentration is not diagnostic of hypogonadism, particularly in obese men or when there are discrepancies between clinical symptoms and the laboratory value of testosterone. Few laboratories measure free testosterone, and a common practice is to calculate free testosterone using algorithms available on the internet. A recent publication draws attention to the potential inaccuracies of these calculations. Measurement of total testosterone, the formulae used to calculate free testosterone and, to a lesser extent, measurement of sex hormone-binding globulin, are potential sources of inaccuracies [33]. There are no generally accepted lower limits of normal for free testosterone 
for the diagnosis of hypogonadism. However, a free testosterone level below $225 \mathrm{pmol} \mathrm{L}^{-1}\left(65 \mathrm{pg} \mathrm{mL}^{-1}\right)$ can provide supportive evidence for testosterone treatment [31]. Threshold values for bioavailable testosterone depend on the method used and are not generally available. Equilibrium dialysis is the gold standard for free testosterone measurement. Free testosterone assays based on analog displacement immunoassays are widely available but do not give an accurate measurement of free testosterone; thus they should not be used [31]. Alternately, measuring serum SHBG levels together with reliable serum total testosterone levels provides the data necessary for calculating free testosterone levels. Calculated free testosterone correlates well with free testosterone by equilibrium dialysis [31]. Efforts to create standardization of testosterone assays, agreement on standards for testosterone measurement and accurate reference ranges for testosterone by liquid chromatography-mass spectrometry (LC-MS)/ MS are being developed. International reference standards, characterization of methodology, and population-based reference ranges for free testosterone by equilibrium dialysis are needed. Consensus on the equilibrium constants for testosterone binding to SHBG and albumin will allow improved calculation of free testosterone [31]. Salivary testosterone has also been shown to be a reliable substitute for free testosterone measurements but cannot be recommended for general use at this time, since the methodology has not been standardized and adult male ranges are not available in most hospital or reference laboratories [31]. Again, only longer-term studies can resolve whether these methods of determining testosterone deficiency in elderly men have made contribution to their well-being.

\section{Benefits of testosterone of replacement therapy}

Restoring testosterone levels to within the normal range by using testosterone replacement therapy can improve many of the effects of hypogonadism. In the past decade evidence has been produced of the benefit of androgen treatment on multiple target organs of hypogonadal men, and recent studies show short-term beneficial effects of testosterone in older men that are similar to those in younger men [34-37].

There may be beneficial effects on mood, energy levels and patients' sense of well-being, sexual function, lean body mass (LBM) and muscle strength, erythropoiesis and BMD, cognition and some benefits on cardiovascular risk factors. The following is a summary of studies examing the effects of testosterone replacement in mainly elderly men.

\subsection{Improving metabolic syndrome and diabetes type 2, cardiovascular disease}

Many of the components of the metabolic syndrome (obesity, hypertension, dyslipidemia impaired glucose regulation, and insulin resistance) are also present in hypogonadal men. Lower testosterone levels are associated with surrogate markers for cardiovascular disease, including less favorable carotid intima medial thickness [38] ankle/brachial index as a measure of peripheral arterial disease [39] and calcific aortic atheroma [40]. Endogenous testosterone concentrations are inversely related to mortality due to cardiovascular disease of all causes. There is a positive correlation between serum testosterone levels and insulin sensitivity in men across the full spectrum of glucose tolerance [41] and an improvement of insulin sensitivity was noted after testosterone replacement. The effects of testosterone administration on glycemic control of men with diabetes mellitus were until recently much less certain [42] but there are recent reports indicating a favorable effect of testosterone in addition to diet and exercise [43]. By increasing LBM and reducing fat mass, testosterone therapy modulates insulin resistance and risk of metabolic syndrome [42]. The mechanism of the fall in lipids might be related to the decrease in the visceral abdominal fat mass under the influence of androgens, which inhibit lipoprotein lipase activity and increase lipolysis [44], with improvement of insulin sensitivity and mobilization of triglycerides from abdominal fat tissue. Low androgen levels are associated with an increased risk of cardiovascular disease in men. But data are lacking as to whether higher testosterone levels predict reduced incidence of combined nonfatal and fatal major cardiovascular events [45]. The inverse correlation between $\mathrm{T}$ levels and the severity of coronary artery disease [46] may be related to the fact that low androgen levels are accompanied by an accumulation of abdominal visceral fat $[47,48]$ associated with increased cardiovascular risk factors, impaired glucose tolerance, and non-insulindependent diabetes mellitus [49].

Testosterone replacement therapy does not increase the incidence of cardiovascular disease or events such as myocardial infarction, stroke, or angina [50]. A meta-analysis [51] in 2007 concluded that the current 
available evidence shows no association between testosterone replacement therapy and cardiac events. However, trials of testosterone therapy generally have not been designed or adequately powered to detect effects on clinically significant cardiovascular events [52]. The outcome of most studies in men report either a favorable or neutral effect of normal testosterone levels on cardiovascular disease in men. The administration of testosterone in physiological concentration increases coronary blood flow in patients with coronary heart disease [53]. Beneficial effects on endothelial function [54] and myocardial ischemia have also been demonstrated $[46,55,56]$ but not on cardiovascular mortality $[53,54]$. Thus, although lower testosterone levels are associated with higher cardiovascular risk and to an extent with mortality in aging men, randomized controlled clinical trials of adequate size and duration are needed to determine whether testosterone therapy will reduce morbidity and mortality from cardiovascular disease in hypogonadal or eugonadal men.

\section{$6.2 B M D$}

Osteopenia, osteoporosis, and fracture prevalence rates are greater in hypogonadal younger and older men [57]. The prevalence of osteoporosis in testosterone deficient males is double that of those with normal testosterone level [58]. Testosterone plays a major role in BMD [59]. Bone density in hypogonadal men of all ages increases under testosterone substitution provided the dose is high enough $[60,61]$, although normal adult bone mass is not reached [62]. Testosterone produces this effect by increasing osteoblastic activity and through aromatization to estrogen reducing osteoclastic activity. Part of the androgen effects on bone are at least partially indirect, mediated via their aromatization product estradiol $[63,64]$. Patients with prostate cancer treated with androgen deprivation therapy have an increased risk of osteoporotic fracture. The role of the $\mathrm{LOH}$ in aging males in bone fracture rate remains to be established [65]. The long-term benefit of testosterone requires further investigation. Trials of the effects of testosterone replacement therapy on BMD yielded mixed results. The pooled results of a meta-analysis suggest a beneficial effect on lumbar spine bone density and equivocal findings on femoral neck BMD. Trials of intramuscular testosterone reported significantly larger effects on lumbar bone density than trials of transdermal testosterone, particularly among patients receiving chronic glucocorticoids. None of studies have been large enough to show a fracture risk reduction with testosterone replacement therapy.

\subsection{Muscle mass and strength}

The aging process is accompanied by significant changes in body composition characterized by decreased fat free mass and increased and redistributed fat mass. These changes can impose functional limitations and increase morbidity [66, 67]. Maximal muscle strength correlates with muscle mass independently of age [68]. In men, declining testosterone levels that occur with aging can be a contributing factor to these changes by direct effect on muscle cells by testosterone or by stimulating IGF-1 expression directly and indirectly leading to increased muscle protein synthesis and growth [69]. Epidemiologic studies have demonstrated a correlation between bioavailable testosterone concentrations and fat-free mass [70]; however, the correlation with grip strength is not clear [70]. Testosterone replacement may be effective in reversing age-dependent body composition changes and associated morbidity [71]. Testosterone administration improves body composition: a decrease of fat mass, increase of $\operatorname{LBM}[37,72,73]$. In most of these studies, the body weight change did not differ significantly. Testosterone therapy was associated with a greater improvement in grip strength than placebo $[37,74,75]$. A recent double-blind placebo-controlled study showed benefits of testosterone administration on skeletal muscle performance in elderly men with chronic heart failure [76], and another one found positive effects on the prevention of loss of muscle strength of the lower limbs [77]. Changes in lowerextremity muscle strength and measures of physical function were reported in only a few studies and were inconsistent. Recent cross-sectional studies showed that in aging men there are also positive correlations between testosterone and muscle strength parameters of upper and lower extremities, as measured by leg extensor strength and isometric hand grip strength [78]. Moreover, testosterone was positively associated with functional parameters, including the doors test as well as "get up and go" test, and 5-chair sit/stand test [79]. By contrast, some studies have found an increase in LBM but no change in physical function [80] or an increase in strength of knee extension or flexion. Although there is a potential role of testosterone in the management of frailty, it is not known whether 
testosterone replacement improves physical function and other health-related outcomes, or reduces the risk of disability, falls, or fractures in older men with low testosterone levels [81].

\subsection{Improved sexual desire, function and performance}

The prevalence of ED increases markedly with age $[82,83]$. Serum-free testosterone was significantly correlated with erectile and orgasmic function domains of the International Index of Erectile Function (IIEF) questionnaire. Compared with younger men, elderly men require higher levels of circulating testosterone for libido and erectile function [84, 85]. However, and/ or diminished libido with or without a testosterone deficiency, might be related to other co-morbidities or medications [86].

Men with ED and/or diminished libido and documented testosterone deficiency are candidates for testosterone therapy. Adequate testosterone treatment can restore venous leakage in the corpus cavernosum which is a frequent etiological factor in ED in elderly men [87]. Overviews of randomized controlled clinical trials indicate some benefit of testosterone therapy on sexual health-related outcomes [88]. Long-term follow-up of testosterone replacement in hypogonadal males and a control group indicates that self-assessment of libido was significantly higher in the testosterone-treated group [50]. Testosterone replacement has also been shown to enhance libido and the frequency of sexual acts and sleep-related erections [75, 89].

Transdermal testosterone replacement therapy, in particular, has been linked to positive effects on fatigue, mood, and sexual function, as well as significant increases in sexual activity [90]. In the presence of a clinical picture of testosterone deficiency and borderline serum testosterone levels, a short therapeutic trial may be tried. There is evidence that the combined use of testosterone and PDE5 inhibitors in hypogonadal or borderline eugonadal men have a synergetic effect $[45,91-93]$. The combination treatment should be considered in hypogonadal patients with ED failing to respond to either treatment alone. Testosterone produces this effect by enhancing the production of nitric oxide synthase.

\subsection{Lower urinary tract symptoms}

In addition to improvement in sexual function, testosterone therapy may also improve lower urinary tract symptomatology/bladder functions by increasing bladder capacity and compliance and decreasing detrusor pressure at maximal flow in men with $\mathrm{LOH}[11,94]$.

\subsection{Mood and energy and quality of life ( $Q o L)$}

Men older than 50 years with low free testosterone levels had poorer QoL. Hypogonadal men commonly complain of loss of libido, dysphoria, fatigue, and irritability $[95,96]$. These symptoms overlap with signs and symptoms of major depression. There is significant inverse correlation between bioavailable testosterone levels (but not with total testosterone) and a depression score in elderly men, independent of age and weight [97]. There was a reduced libido and reduced feelings of well being and minimal effect on mood in patients with induced testosterone deficiency; the depressive symptoms during the hypogonadal state were reversed by testosterone replacement [98]. Testosterone replacement therapy has variable effects on mood, energy and sense of well being. The results of placebo-controlled randomized trials on testosterone's effect on QoL and depressive mood were inconsistent across trials and imprecise $[99,100]$. Testosterone administered to nondepressed eugonadal men at physiological doses, did not result in significant effects on mood [101, 102]. In hypogonadal men, testosterone replacement was associated with improved mood and well-being, and reduced fatigue and irritability [103-105]. Randomized controlled trials of testosterone therapy in men without or with underlying chronic illness using a variety of testosterone formulations, report equivocal improvements in QoL measures, including general well-being and fatigue [106, 107]. For patients with major depression and/or dysthymia, improvement was equal to that achieved with standard antidepressants with significant improvement in the depression inventory score. This effect may be a direct effect of testosterone or related to positive effects of testosterone on weight and/or other anthropometric indices. Additional studies are needed to assess the effects of testosterone on clinical depression indices in human immunodeficiency virusinfected patients $[108,109]$. No relationship between testosterone level and depressive symptoms was found in the Massachusetts Male Aging Study. This discrepancy in the results of the effects of testosterone replacement therapy on mood may be explained by the genetic polymorphism in the androgen receptor which defines a vulnerable group in whom depression is expressed when testosterone levels fall below a 
particular threshold $[110,111]$.

\subsection{Cognitive function}

Age-related decreases in bioavailable testosterone predicted age-related decline in visual and verbal memory. There is good evidence for a strong correlation between testosterone levels and cognitive performance, such as spatial abilities or mathematical reasoning. Higher bioavailable and free testosterone concentrations have each been associated with better performance in specific aspects of memory and cognitive function, with optimal processing capacity found in men ranging from 35 to 90 years of age, even after adjustment for potential confounders including age, educational attainment and cardiovascular morbidity $[112,113]$. whereas total testosterone was not [114]. However, contradictory findings have also been reported. In men undergoing hormonal therapy for prostate cancer, suppression of endogenous testosterone synthesis and blockade of the androgen receptor resulted in a beneficial effect on verbal memory but an adverse effect on spatial ability [115] and visuomotor showing a slowed reaction times in several attentional domains. While the outcome of these studies looks promising, there is as yet no definitive proof of the beneficial effects of restoring testosterone levels to normal in elderly men on clinical parameters. Trials of testosterone therapy in men to evaluate its effects on measures of cognitive function and memory to date were all relatively small and of a relatively short duration and have shown mixed results [116, 117]. Transdermal testosterone treatment in men aged 34 to 70 years improved verbal memory and spatial memory respectively [118] and intramuscular testosterone improved verbal and spatial memory and constructional abilities in non-hypogonadal men with mild cognitive impairment and Alzheimer's disease [119]. In one study of healthy men aged 50 to 90 years, intramuscular testosterone alone or in combination with the aromatase inhibitor anastrozole improved spatial memory, whereas verbal memory only improved in testosterone-treated men in the absence of anastrozole, raising the possibility that part of the effect of exogenous testosterone is mediated by its aromatization to estradiol [119]. Although the evidence from observational studies is not uniform, lower free testosterone appears to be associated with poorer outcomes on measures of cognitive function, particularly in older men and testosterone therapy in hypogonadal men may have some benefit for cognitive performance.

\subsection{Improving anemia}

Endogenous androgens are known to stimulate erythropoiesis; increase reticulocyte count, blood hemoglobin levels and bone marrow erythropoietic activity in mammals, whereas castration has opposite effects. Testosterone deficiency results in a $10 \%$ to $20 \%$ decrease in the blood hemoglobin concentration, which can result in anemia [120,121]. Young hypogonadal men usually have fewer red blood cells and lower hemoglobin levels than age-matched controls, whilst healthy older men also may have lower hemoglobin than normal young men.

\section{Safety of testosterone administration to elderly men}

The progressive decline of testosterone in aging men is supported by scientific evidence $[1,3]$. Whether older hypogonadal men will benefit from testosterone treatment and what will be the risks associated with such intervention can only be resolved by sufficiently powered studies. Data on the risks of testosterone administration are needed, particularly on its safety in elderly men [31, 122]. It is unlikely that rigorous scientific data with regard to safety of testosterone administration to elderly men will become available soon. Such studies would include 5 000-7 000 men and would require 5-7 years of observation. So, for the time being, smaller scale studies will have to be utilized to garner information on safety. The main side effects of testosterone administration are listed below.

\subsection{Polycythemia}

There is curvilinear relationship in men (not receiving testosterone administration) between plasma testosterone levels and hemoglobin [22]. Testosterone exerts its effect on erythropoiesis through a number of mechanisms. Testosterone has an effect on erythropoietin production in the kidney [123] but it has also a direct effect on colony formation of progenitor cells of erythrocytes [124]. In a study by Wang [95], a dose dependent effect of testosterone could be established on hemoglobin and the hematocrit values. This dose-dependency was also apparent from another study [125], which compared the effects of transdermal versus intramuscular testosterone; the latter achieved higher plasma levels of testosterone and raised the hematocrit more than transdermal testosterone. In a recent study it was convincingly confirmed that 
testosterone has a dose-dependent stimulatory effect on hematopoiesis in men. Remarkably, this effect was more pronounced in older men [121]. Also other studies confirmed the relevance of the dose of testosterone [126] and of age as factors in the stimulation of hematopoiesis [127]. Also obesity and shorter CAG repeats appeared to be factors [22].

A higher value of the hematocrit is associated with stroke [128, 129], and coronary heart disease [130]. However, a relation between increased hematocrit as a result of androgen supplementation as such and an increased risk for stroke or any cardiovascular event in general has not been demonstrated by a large metaanalysis of placebo-controlled trials of testosterone administration to (elderly) men [131]. Polycythemia ia a manageable risk of androgen administration when hemoglobin levels and the hematocrit are monitored and the dose of testosterone is adjusted.

\subsection{Lower urinary tract symptoms and prostate disease}

Several follow-up studies of men receiving testosterone treatment [131-133] have failed to demonstrate an exacerbation of voiding symptoms due to benign prostatic hyperplasia. Complications such as urinary retention in therapy group did not occur at higher rates than in controls receiving placebo.

The occurrence of prostate cancer after testosterone administration to (elderly) men has been reported [134138]. By contrast, a variety of studies, using various designs and testosterone formulations, over periods ranging from several months to 15 years, in men with a wide range of ages, have not revealed an increased risk of prostate cancer [139-154]. A meta-analysis found that testosterone treatment in older men compared to placebo was not associated with a significantly higher risk of detection of prostate cancer [131], although the frequency of prostate biopsies was much higher in the testosterone-treated group than in the placebo group [131].

The above applies also to the assessment of safety of testosterone administration to elderly men. There is no convincing evidence that testosterone is a main factor in the development of prostate cancer in elderly men and guidelines for monitoring have been developed which, if rigorously applied, render testosterone administration to elderly men acceptably safe therapy in men without a prior history of prostate carcinoma or without evidence of harboring a prostate carcinoma. There are now at least three publications demonstrating a lack of prostate carcinoma recurrence with testosterone therapy after definitive prostate carcinoma treatment. Two articles have reported no prostate-specific antigen (PSA) recurrence in a total of 17 men, following radical prostatectomy in men with undetectable PSA $[155,156]$. A third study reported that no cancer recurrence was noted in 31 hypogonadal men treated with brachytherapy with a follow-up of approximately 5 years [157]. These small studies suggest that normalization of testosterone in men who have shown no signs of recurrence of prostate cancer after treatment, could benefit from testosterone replacement.

The case of an 84-year-old man with hypogonadism, with biopsy-proven prostate cancer (Gleason 6 cancer in both lobes), treated with testosterone gel for 2 years has been reported. In this man a decline of serum PSA was noted over the treatment period [158].

There is a consensus now that administration of testosterone to elderly men is a responsible practice provided certain guidelines of professional bodies are followed with regard to testosterone administration to elderly men $[31,122]$. This consensus is based on expert opinion and there remains an urgent need for longer-term safety studies.

\subsection{Cardiovascular disease}

Until a decade ago, it was a widely held belief that androgens have an atherogenic effect and thus led to cardiovascular disease, and androgen administration was regarded as adding to the risk of developing cardiovascular disease. Over the last decade several papers have examined the relationship of androgens with cardiovascular disease and concluded that it is no longer tenable to regard testosterone as a culprit in the etiology of cardiovascular disease [159-163]. Recent epidemiological studies have found that low testosterone levels are a predictor of mortality in elderly men [164-168]. Over the last 2 years a large number of review papers have highlighted the significance of depressed levels of testosterone and cardiovascular disease [4, 6, 169].

Studies of testosterone replacement in men have not reported problems with peripheral edema or exacerbation of hypertension or congestive heart failure, but because current data were largely collected from relatively healthy older men, the possible impact of fluid retention on chronically ill or more frail individuals should be considered. Modest, usually transient, leg edema and 
fluid retention (up to several kilograms in weight gain) is possible, especially within the first few months of testosterone replacement therapy [5].

\subsection{Sleep apnea}

Obstructive sleep apnea ayndrome (OSAS) is characterized by snoring, repetitive episodes of upper airway occlusion resulting in hypoxemia and sleep fragmentation and excessive daytime sleepiness [170]. OSAS is also associated with loss of libido and ED [171-172]. It has been estimated that $10 \%$ to $60 \%$ of patients with OSAS suffer from ED.

Obesity, and more specifically, the metabolic syndrome is common in patients with OSAS [173, 174]. OSAS is associated with an increased risk of hypertension, arrhythmia, myocardial infarction, stroke, and sudden death. Sexual dysfunction associated with OSAS may also be explained by the metabolic syndrome $[175,176]$. Men with OSAS have lowered plasma testosterone levels [177] but this association was largely explained by adiposity in agreement with the finding that the metabolic syndrome is associated with reduced plasma testosterone values [178, 175]. In a large meta-analysis of placebo-controlled trials of testosterone administration to (elderly) men [131], the frequency of sleep apnea was not significantly different between the two groups. Nevertheless, it is safe to consider obstructive pulmonary disease in overweight persons or heavy smokers as a relative contra-indication.

\section{Conclusion}

There is a host of studies in elderly men with lower-than-normal testosterone reporting improvement of features of the metabolic syndrome, of BMD, of mood and of sexual functioning. While the outcome of these studies looks promising, there is as yet no definitive proof of the beneficial effects of restoring testosterone levels to normal in elderly men on clinical parameters. Few of these studies meet as yet rigorous standards of scientific enquiry: double-blind, placebocontrolled design of the study. The endpoints of the studies are usually surrogate markers of disease and not clinical endpoints such as improvement and prevention of cardiovascular disease, diabetes mellitus type 2, osteopenia/osteoporosis, less fractures and less frailty. Admittedly, studies to prove the latter are difficult to undertake in view of the costs and the long duration of such studies. It is difficult to compare these studies because of the intrinsic difficulties in establishing the degree of hypogonadism in the various studies: laboratory outcomes may vary between laboratories and a certain laboratory value of testosterone does not mean the same for various men on the basis of properties of their androgen receptors.

The above applies also to the assessment of safety of testosterone administration to elderly men. There is convincing evidence that testosterone is not a main factor in the development of prostate cancer in elderly men and guidelines for monitoring have been developed which, if rigorously applied, render testosterone administration to elderly men acceptably safe.

\section{References}

1 Kaufman JM, Vermeulen A. The decline of androgen levels in elderly men and its clinical and therapeutic implications. Endocr Rev 2005; 26: 833-76.

2 Araujo AB, O'Donnell AB, Brambilla DJ, Simpson WB, Longcope $\mathrm{C}$, et al. Prevalence and incidence of androgen deficiency in middle-aged and older men: estimates from the Massachusetts Male Aging Study. J Clin Endocrinol Metab 2004; 89: 5920-6.

3 Liu PY, Beilin J, Meier C, Nguyen TV, Center JR, et al. Age-related changes in serum testosterone and sex hormone binding globulin in Australian men: longitudinal analyses of two geographically separate regional cohorts. J Clin Endocrinol Metab 2007; 92: 3599-603.

4 Yassin AA, Saad F, Gooren LJ. Metabolic syndrome, testosterone deficiency and erectile dysfunction never come alone. Andrologia 2008; 40: 259-64.

5 Tenover JL. Testosterone replacement therapy in older adult men. Int J Androl 1999; 22: 300-6.

6 Traish AM, Saad F, Guay A. The dark side of testosterone deficiency: II. Type 2 diabetes and insulin resistance. J Androl 2009; 30: 23-32.

7 Traish AM, Feeley RJ, Guay A. Mechanisms of obesity and related pathologies: androgen deficiency and endothelial dysfunction may be the link between obesity and erectile dysfunction. Febs J 2009; 276: 5755-67.

8 Saad F, Gooren L. The role of testosterone in the metabolic syndrome: a review. J Steroid Biochem Mol Biol 2009; 114: 40-3.

9 Traish AM, Goldstein I, Kim NN. Testosterone and erectile function: from basic research to a new clinical paradigm for managing men with androgen insufficiency and erectile dysfunction. Eur Urol 2007; 52: 54-70.

10 McVary K. Lower urinary tract symptoms and sexual dysfunction: epidemiology and pathophysiology. BJU Int 2006; 97 Suppl 2: 23-8; discussion 44-5.

11 Haider A, Gooren LJ, Padungtod P, Saad F. Concurrent improvement of the metabolic syndrome and lower urinary tract symptoms upon normalisation of plasma testosterone levels in hypogonadal elderly men. Andrologia 2009; 41: 
$7-13$.

12 Handelsman DJ, Liu PY. Andropause: invention, prevention, rejuvenation. Trends Endocrinol Metab 2005; 16: 39-45.

13 Kelleher S, Conway AJ, Handelsman DJ. Blood testosterone threshold for androgen deficiency symptoms. J Clin Endocrinol Metab 2004; 89: 3813-7.

14 Zitzmann M, Nieschlag E. The CAG repeat polymorphism within the androgen receptor gene and maleness. Int J Androl 2003; 26: 76-83.

15 Zitzmann M. Mechanisms of disease: pharmacogenetics of testosterone therapy in hypogonadal men. Nat Clin Pract Urol 2007; 4: 161-6.

16 Mohr BA, Guay AT, O'Donnell AB, McKinlay JB. Normal, bound and nonbound testosterone levels in normally ageing men: results from the Massachusetts Male Ageing Study. Clin Endocrinol (Oxf) 2005; 62: 64-73.

17 Wu FC, Tajar A, Pye SR, Silman AJ, Finn JD, et al. Hypothalamic-pituitary-testicular axis disruptions in older men are differentially linked to age and modifiable risk factors: the European Male Aging Study. J Clin Endocrinol Metab 2008; 93: 2737-45.

18 Gooren LJ. Androgen levels and sex functions in testosterone-treated hypogonadal men. Arch Sex Behav 1987; 16: 463-73.

19 Bagatell CJ, Heiman JR, Rivier JE, Bremner WJ. Effects of endogenous testosterone and estradiol on sexual behavior in normal young men. J Clin Endocrinol Metab 1994; 78: 711-6.

20 Woodhouse LJ, Reisz-Porszasz S, Javanbakht M, Storer TW, Lee $\mathrm{M}$, et al. Development of models to predict anabolic response to testosterone administration in healthy young men. Am J Physiol Endocrinol Metab 2003; 284: E1009-17.

21 Saad F, Gooren LJ, Haider A, Yassin A. A dose-response study of testosterone on sexual dysfunction and features of the metabolic syndrome using testosterone gel and parenteral testosterone undecanoate. J Androl 2008; 29: 102-5.

22 Zitzmann M, Faber S, Nieschlag E. Association of specific symptoms and metabolic risks with serum testosterone in older men. J Clin Endocrinol Metab 2006; 91: 4335-43.

23 Bancroft J. The endocrinology of sexual arousal. J Endocrinol 2005; 186: 411-27.

24 Aversa A, Isidori AM, Spera G, Lenzi A, Fabbri A. Androgens improve cavernous vasodilation and response to sildenafil in patients with erectile dysfunction. Clin Endocrinol (Oxf) 2003; 58: 632-8.

25 O'Donnell AB, Araujo AB, McKinlay JB. The health of normally aging men: The Massachusetts Male Aging Study (1987-2004). Exp Gerontol 2004; 39: 975-84.

26 Nieschlag E, Swerdloff R, Behre HM, Gooren LJ, Kaufman $\mathrm{JM}$, et al. Investigation, treatment and monitoring of lateonset hypogonadism in males. ISA, ISSAM, and EAU recommendations. Eur Urol 2005; 48: 1-4.

27 Feldman HA, Longcope C, Derby CA, Johannes CB, Araujo $\mathrm{AB}$, et al. Age trends in the level of serum testosterone and other hormones in middle-aged men: longitudinal results from the Massachusetts male aging study. J Clin Endocrinol Metab 2002; 87: 589-98.
28 Nieschlag E, Behre HM, Bouchard P, Corrales JJ, Jones TH, et al. Testosterone replacement therapy: current trends and future directions. Hum Reprod Update 2004; 10: 409-19.

29 Kshirsagar A, Seftel A, Ross L, Mohamed M, Niederberger C. Predicting hypogonadism in men based upon age, presence of erectile dysfunction, and depression. Int J Impot Res 2006; 18: 47-51.

30 Black AM, Day AG, Morales A. The reliability of clinical and biochemical assessment in symptomatic lateonset hypogonadism: can a case be made for a 3-month therapeutic trial? BJU Int 2004; 94: 1066-70.

31 Wang C, Nieschlag E, Swerdloff R, Behre HM, Hellstrom $\mathrm{WJ}$, et al. Investigation, treatment, and monitoring of lateonset hypogonadism in males: ISA, ISSAM, EAU, EAA, and ASA Recommendations. Eur Urol 2009; 55: 121-30.

32 Reyes-Vallejo L, Lazarou S, Morgentaler A. Subjective sexual response to testosterone replacement therapy based on initial serum levels of total testosterone. J Sex Med 2007; 4: $1757-62$

33 Sartorius G, Ly LP, Sikaris K, McLachlan R, Handelsman DJ. Predictive accuracy and sources of variability in calculated free testosterone estimates. Ann Clin Biochem 2009; 46: 137-43.

34 Allan CA, Strauss BJ, Burger HG, Forbes EA, McLachlan RI. Testosterone therapy prevents gain in visceral adipose tissue and loss of skeletal muscle in nonobese aging men. J Clin Endocrinol Metab 2008; 93: 139-46.

35 Swerdloff RS, Wang C. Three-year follow-up of androgen treatment in hypogonadal men: preliminary report with testosterone gel. Aging Male 2003; 6: 207-11.

36 Bhasin S, Woodhouse L, Casaburi R, Singh AB, Mac RP, et al. Older men are as responsive as young men to the anabolic effects of graded doses of testosterone on the skeletal muscle. J Clin Endocrinol Metab 2005; 90: 678-88.

37 Page ST, Amory JK, Bowman FD, Anawalt BD, Matsumoto $\mathrm{AM}$, et al. Exogenous testosterone (T) alone or with finasteride increases physical performance, grip strength, and lean body mass in older men with low serum T. J Clin Endocrinol Metab 2005; 90: 1502-10.

38 Muller M, van den Beld AW, Bots ML, Grobbee DE, Lamberts SW, et al. Endogenous sex hormones and progression of carotid atherosclerosis in elderly men. Circulation 2004; 109: 2074-9.

39 Tivesten A, Mellstrom D, Jutberger H, Fagerberg B, Lernfelt $\mathrm{B}$, et al. Low serum testosterone and high serum estradiol associate with lower extremity peripheral arterial disease in elderly men. The MrOS Study in Sweden. J Am Coll Cardiol 2007; 50: 1070-6.

40 Hak AE, Witteman JC, de Jong FH, Geerlings MI, Hofman $\mathrm{A}$, et al. Low levels of endogenous androgens increase the risk of atherosclerosis in elderly men: the Rotterdam study. J Clin Endocrinol Metab 2002; 87: 3632-9.

41 Pitteloud N, Mootha VK, Dwyer AA, Hardin M, Lee H, et al. Relationship between testosterone levels, insulin sensitivity, and mitochondrial function in men. Diabetes Care 2005; 28: 1636-42.

42 Kapoor D, Goodwin E, Channer KS, Jones TH. Testosterone replacement therapy improves insulin resistance, glycaemic 
control, visceral adiposity and hypercholesterolaemia in hypogonadal men with type 2 diabetes. Eur J Endocrinol 2006; 154: 899-906.

43 Heufelder AE, Saad F, Bunck MC, Gooren L. Fifty-twoweek treatment with diet and exercise plus transdermal testosterone reverses the metabolic syndrome and improves glycemic control in men with newly diagnosed type 2 diabetes and subnormal plasma testosterone. J Androl 2009; 30: 726-33.

44 Marin P, Lonn L, Andersson B, Oden B, Olbe L, et al. Assimilation of triglycerides in subcutaneous and intraabdominal adipose tissues in vivo in men: effects of testosterone. J Clin Endocrinol Metab 1996; 81: 1018-22.

45 Aversa A, Isidori AM, Greco EA, Giannetta E, Gianfrilli D, et al. Hormonal supplementation and erectile dysfunction. Eur Urol 2004; 45: 535-8.

46 Phillips GB, Pinkernell BH, Jing TY. The association of hypotestosteronemia with coronary artery disease in men. Arterioscler Thromb 1994; 14: 701-6.

47 Seidell JC, Bjorntorp P, Sjostrom L, Kvist H, Sannerstedt $\mathrm{R}$. Visceral fat accumulation in men is positively associated with insulin, glucose, and C-peptide levels, but negatively with testosterone levels. Metabolism 1990; 39: 897-901.

48 Tchernof A, Labrie F, Belanger A, Prud'homme D, Bouchard $\mathrm{C}$, et al. Relationships between endogenous steroid hormone, sex hormone-binding globulin and lipoprotein levels in men: contribution of visceral obesity, insulin levels and other metabolic variables. Atherosclerosis 1997; 133: 235-44.

49 Kabakci G, Yildirir A, Can I, Unsal I, Erbas B. Relationship between endogenous sex hormone levels, lipoproteins and coronary atherosclerosis in men undergoing coronary angiography. Cardiology 1999; 92: 221-5.

50 Hajjar RR, Kaiser FE, Morley JE. Outcomes of long-term testosterone replacement in older hypogonadal males: a retrospective analysis. J Clin Endocrinol Metab 1997; 82: 3793-6.

51 Haddad RM, Kennedy CC, Caples SM, Tracz MJ, Bolona $\mathrm{ER}$, et al. Testosterone and cardiovascular risk in men: a systematic review and meta-analysis of randomized placebocontrolled trials. Mayo Clin Proc 2007; 82: 29-39.

52 Allan CA, McLachlan RI. Age-related changes in testosterone and the role of replacement therapy in older men. Clin Endocrinol (Oxf) 2004; 60: 653-70.

53 Haffner SM, Moss SE, Klein BE, Klein R. Sex hormones and DHEA- $\mathrm{SO}_{4}$ in relation to ischemic heart disease mortality in diabetic subjects. The Wisconsin Epidemiologic Study of Diabetic Retinopathy. Diabetes Care 1996; 19: 1045-50.

54 Barrett-Connor E, Khaw KT. Endogenous sex hormones and cardiovascular disease in men. A prospective populationbased study. Circulation 1988; 78: 539-45.

55 Cauley JA, Gutai JP, Kuller LH, Dai WS. Usefulness of sex steroid hormone levels in predicting coronary artery disease in men. Am J Cardiol 1987; 60: 771-7.

56 Goldberg RB, Rabin D, Alexander AN, Doelle GC, Getz GS. Suppression of plasma testosterone leads to an increase in serum total and high density lipoprotein cholesterol and apoproteins A-I and B. J Clin Endocrinol Metab 1985; 60: 203-7.

57 Meier C, Nguyen TV, Handelsman DJ, Schindler C, Kushnir $\mathrm{MM}$, et al. Endogenous sex hormones and incident fracture risk in older men: the Dubbo Osteoporosis Epidemiology Study. Arch Intern Med 2008; 168: 47-54.

58 Fink HA, Ewing SK, Ensrud KE, Barrett-Connor E, Taylor $\mathrm{BC}$, et al. Association of testosterone and estradiol deficiency with osteoporosis and rapid bone loss in older men. J Clin Endocrinol Metab 2006; 91: 3908-15.

59 Compston JE. Sex steroids and bone. Physiol Rev 2001; 81: 419-47.

60 Svartberg J, Agledahl I, Figenschau Y, Sildnes T, Waterloo K, et al. Testosterone treatment in elderly men with subnormal testosterone levels improves body composition and BMD in the hip. Int J Impot Res 2008; 20: 378-87.

61 Behre HM, Kliesch S, Leifke E, Link TM, Nieschlag E. Long-term effect of testosterone therapy on bone mineral density in hypogonadal men. J Clin Endocrinol Metab 1997; 82: 2386-90.

62 Saggese G, Bertelloni S, Baroncelli GI. Sex steroids and the acquisition of bone mass. Horm Res 1997; 48 Suppl 5: $65-71$.

63 van den Beld AW, de Jong FH, Grobbee DE, Pols HA, Lamberts SW. Measures of bioavailable serum testosterone and estradiol and their relationships with muscle strength, bone density, and body composition in elderly men. J Clin Endocrinol Metab 2000; 85: 3276-82.

64 Michael H, Harkonen PL, Vaananen HK, Hentunen TA. Estrogen and testosterone use different cellular pathways to inhibit osteoclastogenesis and bone resorption. J Bone Miner Res 2005; 20: 2224-32.

65 Center JR, Nguyen TV, Sambrook PN, Eisman JA. Hormonal and biochemical parameters in the determination of osteoporosis in elderly men. J Clin Endocrinol Metab 1999; 84: 3626-35.

66 Bhasin S. Regulation of body composition by androgens. J Endocrinol Invest 2003; 26: 814-22.

67 Frontera WR, Hughes VA, Fielding RA, Fiatarone MA, Evans WJ, et al. Aging of skeletal muscle: a 12-yr longitudinal study. J Appl Physiol 2000; 88: 1321-6.

68 Reed RL, Pearlmutter L, Yochum K, Meredith KE, Mooradian AD. The relationship between muscle mass and muscle strength in the elderly. J Am Geriatr Soc 1991; 39: 555-61.

69 Mauras N, Hayes V, Welch S, Rini A, Helgeson K, et al. Testosterone deficiency in young men: marked alterations in whole body protein kinetics, strength, and adiposity. J Clin Endocrinol Metab 1998; 83: 1886-92.

70 Baumgartner RN, Waters DL, Gallagher D, Morley JE, Garry PJ. Predictors of skeletal muscle mass in elderly men and women. Mech Ageing Dev 1999; 107: 123-36.

71 Mudali S, Dobs AS. Effects of testosterone on body composition of the aging male. Mech Ageing Dev 2004; 125: 297-304.

72 Ferrando AA, Sheffield-Moore M, Paddon-Jones D, Wolfe RR, Urban RJ. Differential anabolic effects of testosterone and amino acid feeding in older men. J Clin Endocrinol 
Metab 2003; 88: 358-62.

73 Harman SM, Blackman MR. The effects of growth hormone and sex steroid on lean body mass, fat mass, muscle strength, cardiovascular endurance and adverse events in healthy elderly women and men. Horm Res 2003; 60: 121-4.

74 Sih R, Morley JE, Kaiser FE, Perry HM 3rd, Patrick P, et al. Testosterone replacement in older hypogonadal men: a $12-$ month randomized controlled trial. J Clin Endocrinol Metab 1997; 82: 1661-7.

75 Morley JE, Perry HM 3rd, Kaiser FE, Kraenzle D, Jensen $\mathrm{J}$, et al. Effects of testosterone replacement therapy in old hypogonadal males: a preliminary study. J Am Geriatr Soc 1993; 41: 149-52.

76 Caminiti G, Volterrani M, Iellamo F, Marazzi G, Massaro $\mathrm{R}$, et al. Effect of long-acting testosterone treatment on functional exercise capacity, skeletal muscle performance, insulin resistance, and baroreflex sensitivity in elderly patients with chronic heart failure a double-blind, placebocontrolled, randomized study. J Am Coll Cardiol 2009; 54: 919-27.

77 Srinivas-Shankar U, Roberts SA, Connolly MJ, MD OC, Adams JE, et al. Effects of testosterone on muscle strength, physical function, body composition, and quality of life in intermediate-frail and frail elderly men: a randomized, double-blind, placebo-controlled study. J Clin Endocrinol Metab 2010 Jan 8. Epub ahead of print.

78 Perry HM 3rd, Miller DK, Patrick P, Morley JE. Testosterone and leptin in older African-American men: relationship to age, strength, function, and season. Metabolism 2000; 49: 1085-91.

79 Breuer B, Trungold S, Martucci C, Wallenstein S, Likourezos $\mathrm{A}$, et al. Relationships of sex hormone levels to dependence in activities of daily living in the frail elderly. Maturitas 2001; 39: 147-59.

80 Snyder PJ, Peachey H, Hannoush P, Berlin JA, Loh L, et al. Effect of testosterone treatment on body composition and muscle strength in men over 65 years of age. J Clin Endocrinol Metab 1999; 84: 2647-53.

81 Bhasin S. Testosterone supplementation for aging-associated sarcopenia. J Gerontol A Biol Sci Med Sci 2003; 58: 1002-8.

82 Lyngdorf P, Hemmingsen L. Epidemiology of erectile dysfunction and its risk factors: a practice-based study in Denmark. Int J Impot Res 2004; 16: 105-11.

83 Selvin E, Burnett AL, Platz EA. Prevalence and risk factors for erectile dysfunction in the US. Am J Med 2007; 120: 151-7.

84 Schiavi RC, Rehman J. Sexuality and aging. Urol Clin North Am 1995; 22: 711-26.

85 Gray PB, Singh AB, Woodhouse LJ, Storer TW, Casaburi $\mathrm{R}$, et al. Dose-dependent effects of testosterone on sexual function, mood, and visuospatial cognition in older men. $\mathrm{J}$ Clin Endocrinol Metab 2005; 90: 3838-46.

86 Morales A, Buvat J, Gooren LJ, Guay AT, Kaufman JM, et al. Endocrine aspects of sexual dysfunction in men. J Sex Med 2004; 1: 69-81.

87 Yassin AA, Saad F. Dramatic improvement of penile venous leakage upon testosterone administration. A case report and review of literature. Andrologia 2006; 38: 34-7.
88 Krause W, Mueller U, Mazur A. Testosterone supplementation in the aging male: which questions have been answered? Aging Male 2005; 8: 31-8.

89 Shabsigh R. The effects of testosterone on the cavernous tissue and erectile function. World J Urol 1997; 15: 21-6.

90 Meikle AW, Arver S, Dobs A, Sanders SW, Mazer NA. Androderm: A Permeation-Enhanced, Non-Scrotal Testosterone Transdermal System for the Treatment of Male Hypogonadism. In: Bhasin S, editor. Phatmacology, Biology, and Clinical Applications of Androgens. New York: Wiley Liss, Inc.; 1996. p449-57.

91 Shabsigh R, Kaufman JM, Steidle C, Padma-Nathan H. Randomized study of testosterone gel as adjunctive therapy to sildenafil in hypogonadal men with erectile dysfunction who do not respond to sildenafil alone. J Urol 2004; 172: 658-63.

92 Greenstein A, Mabjeesh NJ, Sofer M, Kaver I, Matzkin $\mathrm{H}$, et al. Does sildenafil combined with testosterone gel improve erectile dysfunction in hypogonadal men in whom testosterone supplement therapy alone failed? J Urol 2005; 173: 530-2.

93 Greco EA, Spera G, Aversa A. Combining testosterone and PDE5 inhibitors in erectile dysfunction: basic rationale and clinical evidences. Eur Urol 2006; 50: 940-7.

94 Karazindiyanoglu S, Cayan S. The effect of testosterone therapy on lower urinary tract symptoms/bladder and sexual functions in men with symptomatic late-onset hypogonadism. Aging Male 2008; 11: 146-9.

95 Wang C, Swerdloff RS, Iranmanesh A, Dobs A, Snyder PJ, et al. Transdermal testosterone gel improves sexual function, mood, muscle strength, and body composition parameters in hypogonadal men. J Clin Endocrinol Metab 2000; 85: 2839-53.

96 Wang C, Cunningham G, Dobs A, Iranmanesh A, Matsumoto AM, et al. Long-term testosterone gel (AndroGel) treatment maintains beneficial effects on sexual function and mood, lean and fat mass, and bone mineral density in hypogonadal men. J Clin Endocrinol Metab 2004; 89: 2085-98.

97 Barrett-Connor E, Von Muhlen DG, Kritz-Silverstein D. Bioavailable testosterone and depressed mood in older men: the Rancho Bernardo Study. J Clin Endocrinol Metab 1999; 84: 573-7.

98 Schmidt PJ, Berlin KL, Danaceau MA, Neeren A, Haq NA, et al. The effects of pharmacologically induced hypogonadism on mood in healthy men. Arch Gen Psychiatry 2004; 61: 997-1004.

99 Seidman SN, Spatz E, Rizzo C, Roose SP. Testosterone replacement therapy for hypogonadal men with major depressive disorder: a randomized, placebo-controlled clinical trial. J Clin Psychiatry 2001; 62: 406-12.

100 English KM, Steeds RP, Jones TH, Diver MJ, Channer KS. Low-dose transdermal testosterone therapy improves angina threshold in men with chronic stable angina: a randomized, double-blind, placebo-controlled study. Circulation 2000; 102: 1906-11.

101 Tricker R, Casaburi R, Storer TW, Clevenger B, Berman N, et al. The effects of supraphysiological doses of testosterone on angry behavior in healthy eugonadal men-a clinical 
research center study. J Clin Endocrinol Metab 1996; 81: 3754-8.

102 Haren MT, Wittert GA, Chapman IM, Coates P, Morley JE. Effect of oral testosterone undecanoate on visuospatial cognition, mood and quality of life in elderly men with lownormal gonadal status. Maturitas 2005; 50: 124-33.

103 Wang C, Alexander G, Berman N, Salehian B, Davidson T, et al. Testosterone replacement therapy improves mood in hypogonadal men - a clinical research center study. J Clin Endocrinol Metab 1996; 81: 3578-83.

104 Lunenfeld B, Nieschlag E. Testosterone therapy in the aging male. Aging Male 2007; 10: 139-53.

105 Morley JE. Testosterone replacement in older men and women. J Gend Specif Med 2001; 4: 49-53.

106 Livermann CT, Blazer DG, editors. Tetosterone and Aging: Clinical Research Directions. Washington, DC: National Academies Press; 2004.

107 Gruenewald DA, Matsumoto AM. Testosterone supplementation therapy for older men: potential benefits and risks. J Am Geriatr Soc 2003; 51: 101-15; discussion 15.

108 Rabkin JG, Wagner GJ, Rabkin R. Testosterone therapy for human immunodeficiency virus-positive men with and without hypogonadism. J Clin Psychopharmacol 1999; 19: 19-27.

109 Grinspoon S, Corcoran C, Stanley T, Baaj A, Basgoz N, et al. Effects of hypogonadism and testosterone administration on depression indices in HIV-infected men. J Clin Endocrinol Metab 2000; 85: 60-5.

110 Seidman SN, Araujo AB, Roose SP, McKinlay JB. Testosterone level, androgen receptor polymorphism, and depressive symptoms in middle-aged men. Biol Psychiatry 2001; 50: 371-6.

111 Harkonen K, Huhtaniemi I, Makinen J, Hubler D, Irjala K, et al. The polymorphic androgen receptor gene CAG repeat, pituitary-testicular function and andropausal symptoms in ageing men. Int J Androl 2003; 26: 187-94.

112 Barrett-Connor E, Goodman-Gruen D, Patay B. Endogenous sex hormones and cognitive function in older men. J Clin Endocrinol Metab 1999; 84: 3681-5.

113 Yaffe K, Lui LY, Zmuda J, Cauley J. Sex hormones and cognitive function in older men. J Am Geriatr Soc 2002; 50: 707-12.

114 Yeap BB, Almeida OP, Hyde Z, Chubb SA, Hankey GJ, et al. Higher serum free testosterone is associated with better cognitive function in older men, while total testosterone is not. The Health In Men Study. Clin Endocrinol (Oxf) 2008; 68: 404-12.

115 Cherrier MM, Rose AL, Higano C. The effects of combined androgen blockade on cognitive function during the first cycle of intermittent androgen suppression in patients with prostate cancer. J Urol 2003; 170: 1808-11.

116 Hogervorst E, Bandelow S, Combrinck M, Smith AD. Low free testosterone is an independent risk factor for Alzheimer's disease. Exp Gerontol 2004; 39: 1633-9.

117 Beauchet $\mathrm{O}$. Testosterone and cognitive function: current clinical evidence of a relationship. Eur J Endocrinol 2006; 155: 773-81.

118 Cherrier MM, Craft S, Matsumoto AH. Cognitive changes associated with supplementation of testosterone or dihydrotestosterone in mildly hypogonadal men: a preliminary report. J Androl 2003; 24: 568-76.

119 Cherrier MM, Matsumoto AM, Amory JK, Asthana S, Bremner W, et al. Testosterone improves spatial memory in men with Alzheimer disease and mild cognitive impairment. Neurology 2005; 64: 2063-8.

120 Spivak JL. The blood in systemic disorders. Lancet 2000; 355: 1707-12.

121 Coviello AD, Kaplan B, Lakshman KM, Chen T, Singh $\mathrm{AB}$, et al. Effects of graded doses of testosterone on erythropoiesis in healthy young and older men. J Clin Endocrinol Metab 2008; 93: 914-9.

122 Bhasin S, Cunningham GR, Hayes FJ, Matsumoto AM, Snyder PJ, et al. Testosterone therapy in adult men with androgen deficiency syndromes: an endocrine society clinical practice guideline. J Clin Endocrinol Metab 2006; 91: 1995-2010.

123 Cui YG, Tong JS, Pan QQ, Di FS, Jia Y, et al. [Effect of androgen on erythropoietin in patients with hypogonadism]. Zhonghua Nan Ke Xue 2003; 9: 248-51.

124 Kozlov VA, Tsyrlova IG, Zhuravkin IN. [Different effect of testosterone on polypotential stem hematopoietic stem cells and immunocompetent B-lymphocytes]. Zh Mikrobiol Epidemiol Immunobiol 1979: 72-6.

125 Dobs AS, Meikle AW, Arver S, Sanders SW, Caramelli KE, et al. Pharmacokinetics, efficacy, and safety of a permeationenhanced testosterone transdermal system in comparison with bi-weekly injections of testosterone enanthate for the treatment of hypogonadal men. J Clin Endocrinol Metab 1999; 84: 3469-78.

126 Ip FF, di Pierro I, Brown R, Cunningham I, Handelsman DJ, et al. Trough serum testosterone predicts the development of polycythemia in hypogonadal men treated for up to 21 years with subcutaneous testosterone pellets. Eur J Endocrinol 2010; 162: 385-90.

127 Zitzmann M, Nieschlag E. Androgen receptor gene CAG repeat length and body mass index modulate the safety of long-term intramuscular testosterone undecanoate therapy in hypogonadal men. J Clin Endocrinol Metab 2007; 92: 3844-53.

128 Kiyohara Y, Ueda K, Hasuo Y, Fujii I, Yanai T, et al. Hematocrit as a risk factor of cerebral infarction: longterm prospective population survey in a Japanese rural community. Stroke 1986; 17: 687-92.

129 Lee BI, Nam HS, Heo JH, Kim DI. Yonsei Stroke Registry. Analysis of 1,000 patients with acute cerebral infarctions. Cerebrovasc Dis 2001; 12: 145-51.

130 Brown DW, Giles WH, Croft JB. Hematocrit and the risk of coronary heart disease mortality. Am Heart J 2001; 142: 657-63.

131 Calof OM, Singh AB, Lee ML, Kenny AM, Urban RJ, et al. Adverse events associated with testosterone replacement in middle-aged and older men: a meta-analysis of randomized, placebo-controlled trials. J Gerontol A Biol Sci Med Sci 2005; 60: 1451-7.

132 Schultheiss D, Machtens S, Jonas U. Testosterone therapy in the ageing male: what about the prostate? Andrologia 2004; 
36: $355-65$.

133 Morales A. Testosterone treatment for the aging man: the controversy. Curr Urol Rep 2004; 5: 472-7.

134 Ebling DW, Ruffer J, Whittington R, Vanarsdalen K, Broderick GA, et al. Development of prostate cancer after pituitary dysfunction: a report of 8 patients. Urology 1997; 49: $564-8$.

135 Loughlin KR, Richie JP. Prostate cancer after exogenous testosterone treatment for impotence. J Urol 1997; 157: 1845.

136 Curran MJ, Bihrle W 3rd. Dramatic rise in prostate-specific antigen after androgen replacement in a hypogonadal man with occult adenocarcinoma of the prostate. Urology 1999; 53: 423-4.

137 Rhoden EL, Morgentaler A. Risks of testosterone-replacement therapy and recommendations for monitoring. N Engl J Med 2004; 350: 482-92.

138 Sengupta S, Duncan HJ, Macgregor RJ, Russell JM. The development of prostate cancer despite late onset androgen deficiency. Int J Urol 2005; 12: 847-8.

139 Carter HB, Pearson JD, Metter EJ, Chan DW, Andres R, et al. Longitudinal evaluation of serum androgen levels in men with and without prostate cancer. Prostate 1995; 27: 25-31.

140 Heikkila R, Aho K, Heliovaara M, Hakama M, Marniemi $\mathrm{J}$, et al. Serum testosterone and sex hormone-binding globulin concentrations and the risk of prostate carcinoma: a longitudinal study. Cancer 1999; 86: 312-5.

141 Hsing AW. Hormones and prostate cancer: what's next? Epidemiol Rev 2001; 23: 42-58.

142 Morgentaler A, Bruning CO 3rd, DeWolf WC. Occult prostate cancer in men with low serum testosterone levels. Jama 1996; 276: 1904-6.

143 Thompson IM, Goodman PJ, Tangen CM, Lucia MS, Miller GJ, et al. The influence of finasteride on the development of prostate cancer. N Engl J Med 2003; 349: 215-24.

144 Andriole G, Bostwick D, Brawley O, Gomella L, Marberger M, et al. Chemoprevention of prostate cancer in men at high risk: rationale and design of the reduction by dutasteride of prostate cancer events (REDUCE) trial. J Urol 2004; 172: 1314-7.

145 Clark RV, Hermann DJ, Cunningham GR, Wilson TH, Morrill $\mathrm{BB}$, et al. Marked suppression of dihydrotestosterone in men with benign prostatic hyperplasia by dutasteride, a dual 5alpha-reductase inhibitor. J Clin Endocrinol Metab 2004; 89: 2179-84.

146 Andriole GL, Roehrborn C, Schulman C, Slawin KM, Somerville $\mathrm{M}$, et al. Effect of dutasteride on the detection of prostate cancer in men with benign prostatic hyperplasia. Urology 2004; 64: 537-41; discussion 42-3.

147 Giovannucci E, Stampfer MJ, Krithivas K, Brown M, Dahl $\mathrm{D}$, et al. The CAG repeat within the androgen receptor gene and its relationship to prostate cancer. Proc Natl Acad Sci U S A 1997; 94: 3320-3.

148 Chamberlain NL, Driver ED, Miesfeld RL. The length and location of CAG trinucleotide repeats in the androgen receptor N-terminal domain affect transactivation function. Nucleic Acids Res 1994; 22: 3181-6.

149 Tenover JS. Effects of testosterone supplementation in the aging male. J Clin Endocrinol Metab 1992; 75: 1092-8.
150 Marks LS, Mazer NA, Mostaghel E, Hess DL, Dorey FJ, et al. Effect of testosterone replacement therapy on prostate tissue in men with late-onset hypogonadism: a randomized controlled trial. Jama 2006; 296: 2351-61.

151 Morgentaler A. Testosterone replacement therapy and prostate cancer. Urol Clin North Am 2007; 34: 555-63.

152 Yassin A, Saad F. Testosterone treatment in hypogonadal patients does not cause higher incidence of prostate cancer. J Urol 2008; 179: 301.

153 Yassin AA, Saad F. Improvement of sexual function in men with late-onset hypogonadism treated with testosterone only. J Sex Med 2007; 4: 497-501.

154 Coward RM, Simhan J, Carson CC 3rd. Prostate-specific antigen changes and prostate cancer in hypogonadal men treated with testosterone replacement therapy. BJU Int 2009; 103: 1179-83.

155 Kaufman JM, Graydon RJ. Androgen replacement after curative radical prostatectomy for prostate cancer in hypogonadal men. J Urol 2004; 172: 920-2.

156 Agarwal PK, Oefelein MG. Testosterone replacement therapy after primary treatment for prostate cancer. J Urol 2005; 173: 533-6.

157 Sarosdy MF. Testosterone replacement for hypogonadism after treatment of early prostate cancer with brachytherapy. Cancer 2007; 109: 536-41.

158 Morgentaler A. Two years of testosterone therapy associated with decline in prostate-specific antigen in a man with untreated prostate cancer. J Sex Med 2009; 6: 574-7.

$159 \mathrm{Wu}$ FC, von Eckardstein A. Androgens and coronary artery disease. Endocr Rev 2003; 24: 183-217.

160 Liu PY, Death AK, Handelsman DJ. Androgens and cardiovascular disease. Endocr Rev 2003; 24: 313-40.

161 Jones RD, Nettleship JE, Kapoor D, Jones HT, Channer KS. Testosterone and atherosclerosis in aging men: purported association and clinical implications. Am J Cardiovasc Drugs 2005; 5: 141-54.

162 Shabsigh R, Rajfer J, Aversa A, Traish AM, Yassin A, et al. The evolving role of testosterone in the treatment of erectile dysfunction. Int J Clin Pract 2006; 60: 1087-92.

163 Shabsigh R, Katz M, Yan G, Makhsida N. Cardiovascular issues in hypogonadism and testosterone therapy. Am J Cardiol 2005; 96: 67M-72M.

164 Shores MM, Moceri VM, Gruenewald DA, Brodkin KI, Matsumoto AM, et al. Low testosterone is associated with decreased function and increased mortality risk: a preliminary study of men in a geriatric rehabilitation unit. $\mathrm{J}$ Am Geriatr Soc 2004; 52: 2077-81.

165 Shores MM, Matsumoto AM, Sloan KL, Kivlahan DR. Low serum testosterone and mortality in male veterans. Arch Intern Med 2006; 166: 1660-5.

166 Maggio M, Lauretani F, Ceda GP, Bandinelli S, Ling $\mathrm{SM}$, et al. Relationship between low levels of anabolic hormones and 6-year mortality in older men: the aging in the Chianti Area (InCHIANTI) study. Arch Intern Med 2007; 167: 2249-54.

167 Khaw KT, Dowsett M, Folkerd E, Bingham S, Wareham $\mathrm{N}$, et al. Endogenous testosterone and mortality due to all causes, cardiovascular disease, and cancer in men: European 
prospective investigation into cancer in Norfolk (EPICNorfolk) Prospective Population Study. Circulation 2007; 116: 2694-701.

168 Laughlin GA, Barrett-Connor E, Bergstrom J. Low serum testosterone and mortality in older men. J Clin Endocrinol Metab 2008; 93: 68-75.

169 Corona G, Forti G, Maggi M. Why can patients with erectile dysfunction be considered lucky? The association with testosterone deficiency and metabolic syndrome. Aging Male 2008; 11: 193-9.

170 Lopez-Jimenez F, Sert Kuniyoshi FH, Gami A, Somers VK. Obstructive sleep apnea: implications for cardiac and vascular disease. Chest 2008; 133: 793-804.

171 Hoekema A, Stel AL, Stegenga B, van der Hoeven JH, Wijkstra PJ, et al. Sexual function and obstructive sleep apnea-hypopnea: a randomized clinical trial evaluating the effects of oral-appliance and continuous positive airway pressure therapy. J Sex Med 2007; 4: 1153-62.

172 Karkoulias K, Perimenis P, Charokopos N, Efremidis G, Sampsonas F, et al. Does CPAP therapy improve erectile dysfunction in patients with obstructive sleep apnea syndrome? Clin Ter 2007; 158: 515-8.
173 de Sousa AG, Cercato C, Mancini MC, Halpern A. Obesity and obstructive sleep apnea-hypopnea syndrome. Obes Rev 2008; 9: 340-54.

174 Vgontzas AN, Papanicolaou DA, Bixler EO, Hopper K, Lotsikas A, et al. Sleep apnea and daytime sleepiness and fatigue: relation to visceral obesity, insulin resistance, and hypercytokinemia. J Clin Endocrinol Metab 2000; 85: 1151-8.

175 Shabsigh R, Arver S, Channer KS, Eardley I, Fabbri A, et al. The triad of erectile dysfunction, hypogonadism and the metabolic syndrome. Int J Clin Pract 2008; 62: 791-8.

176 Traish AM, Guay A, Feeley R, Saad F. The dark side of testosterone deficiency: I. Metabolic syndrome and erectile dysfunction. J Androl 2009; 30: 10-22.

177 Barrett-Connor E, Dam TT, Stone K, Harrison SL, Redline $\mathrm{S}$, et al. The association of testosterone levels with overall sleep quality, sleep architecture, and sleep-disordered breathing. J Clin Endocrinol Metab 2008; 93: 2602-9.

178 Goncharov NP, Katsya GV, Chagina NA, Gooren LJ. Three definitions of metabolic syndrome applied to a sample of young obese men and their relation with plasma testosterone. Aging Male 2008; 11: 118-22. 